\title{
Geometric morphometry of pupae to identify four medically important flies (Order: Diptera) in Thailand
}

\author{
TANAWAT CHAIPHONGPACHARA ${ }^{1, \bullet}$, PATCHARAPRON TUBSAMUT $^{2}$ \\ ${ }^{1}$ College of Allied Health Science, Suan Sunandha Rajabhat University. Samut Songkhram 75000, Thailand. Tel./fax. +66-835-865775, \\ remail: tanawat.ch@ssru.ac.th \\ ${ }^{2}$ Program of Public Health, College of Allied Health Sciences, Suan Sunandha Rajabhat University. Samut Songkhram 75000, Thailand.
}

Manuscript received: 18 March 2019. Revision accepted: 2 May 2019

\begin{abstract}
Chaiphongpachara T, Tubsamut P. 2019. Geometric morphometry of pupae to identify four medically important flies (Order: Diptera) in Thailand. Biodiversitas 20: 1504-1509. In this study, we evaluated an outline-based geometric morphometric (GM) approach for species identification from pupae of four common flies medically important in Thailand, Chrysomya megacephala, Lucilia cuprina, Musca domestica, and Boettcherisca nathani. For size estimation, mean perimeter length was used. For shape analysis, Elliptic Fourier Analysis was performed to produce the contour shape variables, which was calculated as Normalised Elliptic Fourier coefficients. Then, principal component analysis was performed on the Normalized Fourier coefficients for discriminant analysis, and used to estimate pupal shape variation among the species. The difference in size and shape between the fly species was analyzed using a non-parametric test based on 1000 permutations after Bonferroni correction for the significance level $(p<0.05)$. In the size analysis, the mean perimeter length for pupae of $B$. nathani was the largest $(20.35 \mathrm{~mm})$ followed by $C$. megacephala $(14.73 \mathrm{~mm})$, while that for $M$. domestica was the smallest $(11.82 \mathrm{~mm})$. The size differences were statistically significant between all species $(p<0.05)$. The contour shapes of all pupae were significantly different among all species. The results of this study can be used as a basis for the future application of GM to identify other types of flies via their pupae.
\end{abstract}

Keywords: Chrysomya megacephala, Geometric morphometric analysis, Lucilia cuprina, Musca domestica, Boettcherisca nathani

\section{INTRODUCTION}

Flies are medically important insects for humans worldwide (Killick-Kendrick 1996). The adults of many flies, such as blowflies, house flies, and flesh flies, are mechanical vectors of human pathogens, including viruses (such as rotavirus) (Tan et al. 1997), bacteria (such as Vibrio cholerae and Bacillus spp., Coccobacillus spp., Staphylococcus spp., Micrococcus spp., Streptococcus spp., Acinetobacter spp., Enterobacter spp., Proteus spp., Escherichia spp., Klebsiella spp, and Staphylococcus spp.) (Yap et al. 2008; Nazni et al. 2005), enteric protozoans, bacteria and trophozoites (such as Entamoeba histolytica, Entamoeba coli, Giardia lamblia, and Cryptosporidium spp.) (Getachew et al. 2007), helminth eggs (such as Ascaris lumbricoides, Trichuris trichiura, and Enterobius vermicularis) (Getachew et al. 2007), and fungi (Nazni et al. 2005), to quote a number of examples. In addition, the larval stage of certain flies causes myiasis, an infestation by developing larvae (maggots) beneath the skin (Hall and Wall 1995). Furthermore, the eggs, larval, and pupal (immature) stages of certain fly species are used in forensic entomology to provide evidence for forensic and legal purposes, for example to estimate the minimum time since death (Amendt et al. 2011; Sontigun et al. 2017), and detect death from drug or poisonous substances (Bourel et al. 2001; Lord et al. 2015). It can be speculated that all fly lifecycle stages (eggs, larvae, puparia, and adults) may have medical significance.
Species identification of the pupal stage of medically important flies is often difficult because the pupae of many species exhibit morphological similarity. Although the various parts of the puparia can be used to identify species of flies, they must also use experts because they are small positions, including the shape of the anterior end and posterior spiracle (Sukontason et al. 2007). This is problematic in medical and forensic cases, especially when rapid identification is required (Sontigun et al. 2017; Sontigun et al. 2019). Previous research has been successful using molecular techniques with respect to DNA sequences of the cytochrome c oxidase subunit I (COI) gene to identify puparia of fly species, including Chrysomya megacephala, C. rufifacies, C. pinguis, Hemipyrellia ligurriens, Lucilia porphyrina, L. cuprina, Sarcophaga javanica, and Sarcophaga dux. (99\% to 100\%) in Taiwan (Pung-Jae Hong et al. 2014). Although molecular methods are the most reliable, and currently the most popular, they are relatively costly. Fast, low-cost alternative methods are urgently needed.

Geometric morphometric (GM) techniques are a modern approach recognized as useful for the identification of species in many insects (Dujardin 2011; Chaiphongpachara 2018). Currently, many types of insects that have obstacles in identification by a morphological method in class Insecta has been confirmed such that the GM approach can help solve this problem, such as three members of the mosquito species of the Maculatus group (Anopheles maculatus, An. Sawadwongporni, and An. 
pseudowillmori)(Chaiphongpachara et al. 2019), three Aedes mosquito vectors in Thailand (Sumruayphol et al., 2016), seven taxa of tsetse flies in the Glossina genus: Nemorhina (five species), Glossina (one species) and Austenina (one species) (Kaba et al. 2017), and three Stomoxys flies ( $S$. pullus, $S$. uruma and $S$. indicus) (Changbunjong et al. 2016). The distinctive features of this method are low cost, ease of use, and speed, aspects (Lorenz et al. 2017; Chaiphongpachara et al. 2019) that make it suitable for distinguishing fly species at the pupal stage. Recently, in Thailand, the GM approach has been applied effectively to identify adults of 12 species of blowfly, Chrysomya megacephala, C. chani, C. pinguis, C. rufifacies, C. villeneuvi, C. nigripes, Lucilia cuprina, L. papuensis, $L$. porphyrina, L. sinensis, Hemipyrellia ligurriens, and $H$. pulchra (Sontigun et al. 2017), and 12 species of flesh fly, Boettcherisca nathani, B. peregrina, Lioproctia pattoni, $L$. ruficornis, L. saprianovae, Parasarcophaga brevicornis, $P$. dux, P. scopariiformis, Sarcorohdendorfia antilope, $S$. multivillosa, S. seniorwhitei, and Seniorwhitea princeps (Sontigun et al. 2019). In addition, GM is also successful in identifying eggs of Triatoma carrioni, Panstrongylus chinai, $P$. howardi, and Rhodnius ecuadoriensis (SantillánGuayasamín et al. 2017).

Usually, GM analysis for insect species identification often employs the landmark-based GM approach because it is easy to use and convenient when seeking to digitize anatomical landmarks (Chaiphongpachara 2018; Chaiphongpachara et al. 2019). However, an outline-based GM approach is also another way to analyze using pseudo landmarks for analysis of contours or boundary outlines of insects that cannot use a landmark-based GM approach in identifying species (Dujardin 2017). Therefore, in this study, we evaluated an outline-based GM approach for species identification from pupae of four common flies that are medically important in Thailand, Chrysomya megacephala, Lucilia cuprina, Musca domestica and Boettcherisca nathani, with the aim of overcoming difficulties normally experienced when attempting species identification at this life-cycle stage.

\section{MATERIALS AND METHODS}

\section{Sample collection, identification, and preparation of pupae}

Adult C. megacephala, L. cuprina, M. domestica, and B. nathani were collected at three sites in Samut Songkhram Province, Thailand ) Site $1,13^{\circ} 23^{\prime} 49.1^{\circ} \mathrm{N}$ $100^{\circ} 02^{\prime} 22.0^{\circ} \mathrm{E}$; Site $2,13^{\circ} 21^{\prime} 43.1^{\circ} \mathrm{N} 100^{\circ} 01^{\prime} 22.5^{\circ} \mathrm{E}$; and Site $3,13^{\circ} 22^{\prime} 54.9^{\circ} \mathrm{N} 99^{\circ} 58^{\prime} 49.1^{\circ} \mathrm{E}$ ) via fly traps containing pork liver as bait, following the method of Chaiphongpachara et al. (2018). Collection of trapped flies was performed during the day between $06.00 \mathrm{~h}$ and $18.00 \mathrm{~h}$ in January 2019, once a week (two traps per site). All collected flies were transported to the laboratory at the College of Allied Health Sciences, Suan Sunandha Rajabhat University, Samut Songkhram Provincial Education Center, Thailand for species identification based on morphological characteristics employing taxonomic keys (Tumrasvin and Shinonaga 1978; Carvalho and Mello-Patiu 2008; Kurahashi and Chaiwong 2013). After species identification, C. megacephala, L. cuprina, $M$. domestica, and $B$. nathani were reared in plastic boxes in the laboratory at $28{ }^{\circ} \mathrm{C} \pm 5{ }^{\circ} \mathrm{C}$ and $50 \% \pm 10 \%$ relative humidity, and provided pork liver as food daily until larvae from laid eggs reached the pupal stage.

\section{Geometric morphometric}

In this study, an outline-based GM approach was applied to evaluate the outlines of the $C$. megacephala, $L$. cuprina, M. domestica, and B. nathani pupae.

\section{Sample preparation}

The 2-day old pupae after pupation were used for analysis. Thirty-one individual samples per fly species were measured. Each pupa was placed on a microscope slide and photographed using a Nikon DS-Ri1 SIGHT digital camera coupled to a Nikon AZ 100M stereomicroscope under $40 \times$ magnification. The pupae were arranged in exactly the same position for all samples and photographed only on the anterior surface. All photographs of pupae were digitized for species comparison by GM (Figure 1). Afterward, 10 photographs per species of flies were randomly selected and digitized a second time by the same user for repeatability testing to verify measurement error by calculating the repeatability index, "R" (Arnqvist and Mårtensson 1998).

\section{Size analysis}

The pupal perimeter was employed for size estimation and displayed as quantile boxes to evaluate size variation ( perimeter length) of pupae in four fly species. The difference in perimeter length between the fly species was analyzed using a non-parametric test based on 1000 permutations after Bonferroni correction at the $5 \%$ level of significance.

\section{Shape analysis}

For shape analysis, elliptic Fourier analysis was performed to produce the contour shape variables, which was calculated as normalized elliptic Fourier coefficients (Kuhl and Giardina 1982). Concisely, "the contour of the pupa is decomposed in terms of sine and cosine curves of successive frequencies (called harmonics), and each harmonic is described by four coefficients" (Dujardin 2017). Then, a principal component analysis was performed on the normalized Fourier coefficients for discriminant analysis, and used to estimate pupal shape variation among the species. Shape differences based on the Mahalanobis distance was evaluated using a nonparametric test 1000 permutations after Bonferroni correction at the 5\% level of significance. Mahalanobis distance (generalized distance) was calculated from the discriminant analysis, which is used to evaluate variance and correlation of variables within the a priori defined groups and measuring distances (Lorenz et al. 2017).

After discriminant analysis of final shape variables, a cross-validated classification test based on Mahalanobis distance (called the jackknife classification) was utilized to 
investigate identification accuracy. Finally, a neighborjoining tree was constructed based on Procrustes distances to examine the mean shape similarities among species, which does not mean evolutionary relationships.

\section{Software}

CLIC ( Collecting Landmarks for Identification and Characterization) software (Dujardin and Slice 2007), available at https://xyom-clic.eu, was employed for GM, including five modules: the $\mathrm{COO}$ module for outline digitization, the TET module for preparing the data and conversion from pixels to $\mathrm{mm}$, the FOG module for elliptical Fourier analysis, the VAR module for size analysis, repeatability testing and non-parametric comparisons of means and variances of size, and the PAD module for shape analysis, a cross-validated classification test and permutation-based statistical significance of Mahalanobis distances via $\mathrm{R}$ software, available at https://cran.r-project.org.

\section{RESULTS AND DISCUSSION}

In this study, we applied a GM approach to analyze the size and shape of pupal outlines with the goal of distinguishing four species of medically important flies. Repeatability tests showed strong scores in perimeter length (size) and shape (0.94 and 0.92 , respectively).

In the size analysis, the mean perimeter length for pupae of $B$. nathani was the largest $(20.35 \mathrm{~mm}$ [mean] \pm $0.83 \mathrm{~mm}$ [S.D.]) followed by $C$. megacephala $(14.73 \mathrm{~mm}$ [mean] $\pm 1.57 \mathrm{~mm}$ [S.D.]), while that for $M$. domestica was the smallest $(11.82 \mathrm{~mm}$ [mean] $\pm 0.33 \mathrm{~mm}$ [S.D.] )Table 1). The size differences were statistically significant between all species (permutation test, 1000 cycles, $p<$ 0.05 ) (Table 1). The pupal size distribution for each species is shown in Figure 2.
A

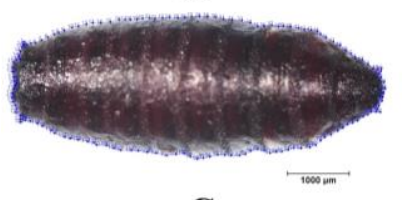

C

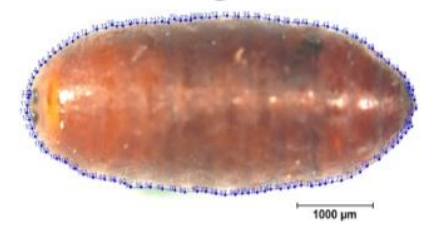

B

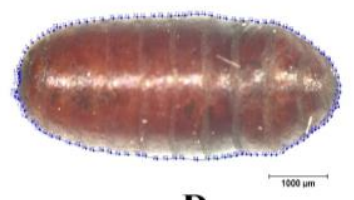

D

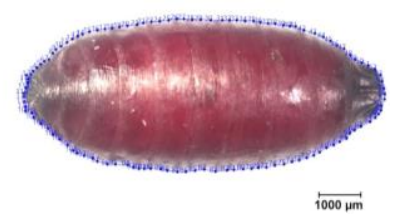

Figure 1. Photographs of pupae of four medically important flies showing the digitally-applied contour. A: C.megacephala, B: L. cuprina, C: M. domestica, and D: B. nathani
Superimposition of the mean contour shapes of the pupae of each fly species showed clear shape differences (Figure 3(. Discriminant analysis indicated the overlay between pupal stages of $L$. cuprina and M. domestica while both $C$. megacephala and $B$. nathani were clearly separated from other types of flies (Figure 4 ). The contour shapes of all pupae were significantly different among all species based on Mahalanobis distances (permutation test, 1000 cycles, $p<0.05$; Table 2). The cross-validated classification scores were excellent, ranging between $90 \%$ and $96 \%$ (Table 3). Three species, C. megacephala, $M$. domestica, and B. nathani, had the same high crossvalidation classification score (96\%). A neighbor-joining tree based on Procrustes distances revealed the similarities between each fly species based on pupal analysis, locating L. cuprina, $M$. domestica, and $C$. megacephala into the same cluster, and B. nathani into another (Figure 5).

Table 1. Mean perimeter length differences of pupal stages of four fly species

\begin{tabular}{lcc}
\hline \multicolumn{1}{c}{ Fly species } & $\begin{array}{c}\text { Pupal centroid size }(\mathbf{m m}), \\
\text { mean } \pm \text { S.D. }\end{array}$ & n \\
\hline C. megacephala & $14.73 \pm 1.57^{\mathrm{a}}$ & 31 \\
L. cuprina & $14.01 \pm 0.38^{\mathrm{b}}$ & 31 \\
M. domestica & $11.82 \pm 0.33^{\mathrm{c}}$ & 31 \\
B. nathani & $20.35 \pm 0.83^{\mathrm{d}}$ & 31 \\
\hline
\end{tabular}

Note: Means with different superscript letters are significantly different at $p<0.05$. Sizes are converted from pixels to $\mathrm{mm}$.

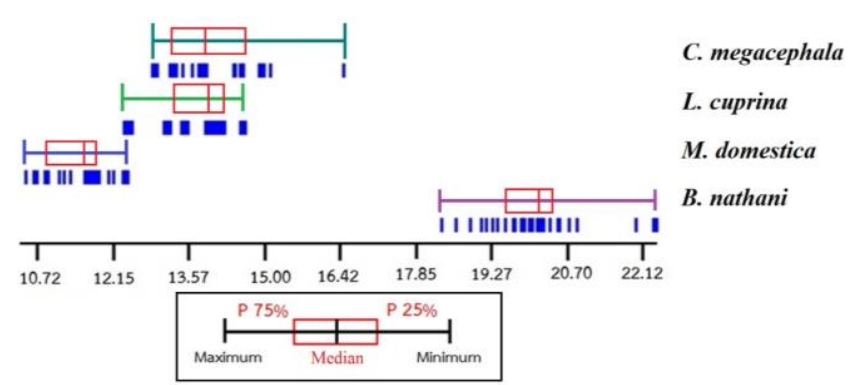

Figure 2. Size distribution of pupae of four fly species. The data are converted from pixels to $\mathrm{mm}$, expressed as median separating the 25 th and 75 th quartiles. The vertical blue bars under each box represent the perimeter length )size( of individual samples.

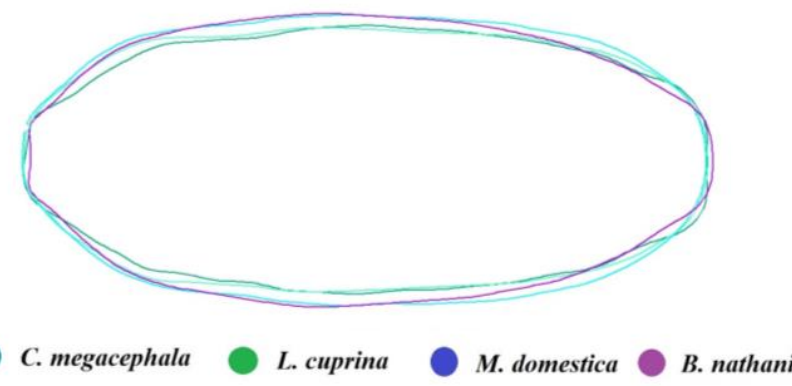

Figure 3. Superimposition of the mean contours of the pupae of four fly species. 


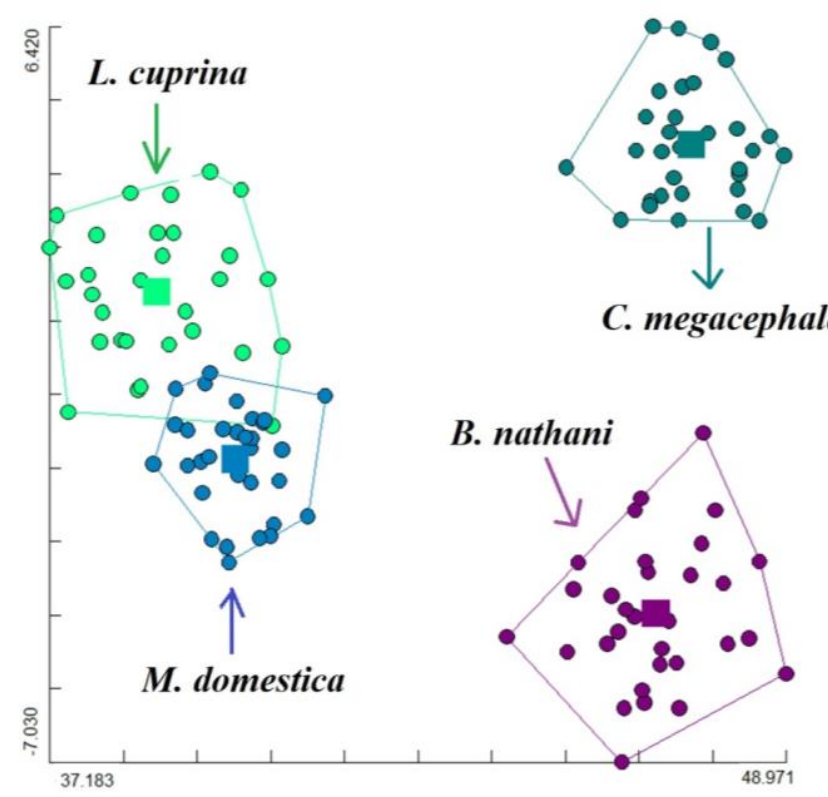

Figure 4. Discriminant analysis to estimate pupal shape variation of four fly species. Factor map of the two discriminant factors based on shape variables in which each point represents an individual. The horizontal axis is the first discriminant factor and the vertical axis is the second discriminant factor.

Table 2. Differences in Mahalanobis distance among four fly species

\begin{tabular}{lccc}
\hline Fly species & C. megacephala & L. cuprina & M. domestica \\
\hline C. megacephala & - & & \\
L. cuprina & $10.34^{*}$ & - & \\
M. domestica & $9.95^{*}$ & $4.45^{*}$ & - \\
B. nathani & $7.71^{*}$ & $0.63^{*}$ & $8.54^{*}$ \\
\hline
\end{tabular}

Note: $*$ indicates a significant difference in shape for a pair $(p<$ $0.05)$.

Table 3. Cross-validated classification for pupae four fly species

\begin{tabular}{lc}
\hline Fly species & $\begin{array}{c}\text { Accuracy of classification (\%) } \\
\text { (assigned/observed) }\end{array}$ \\
\hline C. megacephala & $96) 30 / 31($ \\
L. cuprina & $90) 28 / 31($ \\
M. domestica & $96) 30 / 31($ \\
B. nathani & $96) 30 / 31($ \\
Total & $95) 118 / 124($ \\
\hline
\end{tabular}

Note: Scores represent percent of correctly assigned individuals.

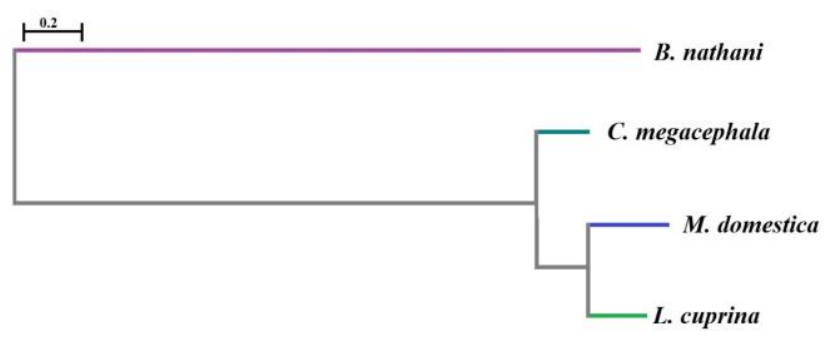

Figure 5. A neighbor-joining tree.

\section{Discussion}

Although C. megacephala, L. cuprina, M. domestica, and $B$. nathani are important in medicine and forensic science, the pupa stage is difficult to distinguish species in and according to type because they are morphologically similar. Previous research has investigated the characteristics of the puparia of both $M$. domestica and $C$. megacephala with scanning electron microscopy (SEM) and found that not only the size, shape, and number of papillae on the anterior spiracle can be used to identify the type of flies, but the number of globules on the bubble membrane can be identified also, which is difficult for a light microscope (Siriwattanarungsee et al. 2005).

In this study, we reported for the first time the application of a GM approach to identify fly species from outlines of their pupae, revealing its potential in using pupae from four medically important flies. GM analysis of pupa size and shape showed differences in all four species. Our results were consistent with previous studies that successfully applied a landmark-based GM approach to identify species of blow flies (Sontigun et al. 2017) and flesh flies (Sontigun et al. 2019) during the adult stage in Thailand. In addition, our results were consistent with previous studies that found that GM was effective in identifying species of biting flies, including tsetse flies (Glossina) as vectors of human African trypanosomiasis (sleeping sickness) (Kaba et al. 2017) and Stomoxys flies as vectors of many pathogens in livestock and wildlife, such as viruses, bacteria, protozoa, and helminth (Changbunjong et al. 2016).

Usually, species identification with the order Diptera using adults and a GM approach does not involve a size factor - size is easily affected by environmental influences (Lorenz et al. 2017; Gomez et al. 2014; Chaiphongpachara and Laojun 2019). Previous research has found size differences of two populations between the natural and experimental population of adult blow flies, Chrysomya albiceps (Wiedemann), and confirmed that environmental conditions have an important effect on body size (Horenstein and Peretti 2012). However, our analysis using pupal size of four medically important flies has shown remarkable differences, indicating that pupal size could prove a valuable factor aiding identification at the genus level. The results of the size analysis of puparia in this study were consistent with previous studies that determined significant differences among the puparia sizes of the seven fly species, including $C$. megacephala, $C$. nigripes, $C$. rufifacies, C. villeneuvi, L.cuprina, Hemipyrellia ligurriens, and $M$. domestica ( $p<0.05)$, of which the length of puparia C. megacephala was larger than L. cuprina and M. domestica, respectively (Sukontason et al. 2007).

Although morphological characteristics at the pupal stage of flies in this study were coarctate and cylindrical in shape, they had different features according to each type of fly. Shape analysis with GM also showed distinct differences in all four species. Discriminant analysis, Mahalanobis distance scores, cross-validated classification scores ) $>90 \%$ (, and neighbor-joining trees all clearly showed differences between the flies. These results via shape analysis clearly showed differences in puparia of the 
four fly species. Morphological puparia can identify different species, such as the shape of the anterior end and posterior spiracle, which is a unique characteristic for distinguishing puparia of closely related species (Sukontason et al. 2007). Recently, Pung-Jae Hong et al. (2014) studied the identification of puparia of forensically important fly Species (Diptera: Calliphoridae and Sarcophagidae), including C. megacephala, C. rufifacies, C. pinguis, $H$. ligurriens, L. porphyrina, L. cuprina, Sarcophaga javanica, and Sarcophaga dux. In Taiwan, through SEM, it was found that the morphological characteristics of puparia were different in certain types and species, including posterior spiracles on the caudal segment, shape of wrinkled head, number of papilla on each anterior spiracle, dorsal spines on the sixth abdominal segments, and grain pattern beside posterior spiracles. This supports how the morphology of the pupal shape can be used to identify certain types and species of flies, including C. megacephala, L. cuprina, M. domestica, and B. nathani.

Overall, our results indicate the effectiveness of GM analysis for fly identification from pupae. The GM approach usually employs insect wings (rather than other organs) because wings are essentially bi-dimensional structures (Wilke et al. 2016; Dujardin 2017). However, previous studies have been successful applying an outlinebased GM approach to identify species of arthropods by analyzing other organs, such as the scutum in trombiculid mites within the genus, Walchia (Sungvornyothin et al. 2018), or by using the contour of soft ticks (family Argasidae) (Dujardin et al. 2014), and the contour of eggs of Triatominae (Santillán-Guayasamín et al. 2017). The results from those studies were consistent with our results using fly pupae.

To conclude, the results of this study can be employed as a basis for the future application of the GM approach to identify other types of flies via their pupae.

\section{ACKNOWLEDGEMENTS}

This study was supported by the College of Allied Health Sciences, Suan Sunandha Rajabhat University, Thailand.

\section{REFERENCES}

Amendt J, Richards CS, Campobasso CP, Zehner R, Hall MJR. 2011 Forensic entomology: applications and limitations. Forensic Sci Med Pathol 7 (4): 379-392.

Arnqvist G, Martensson T. 1998. Measurement error in geometric morphometrics: Empirical strategies to assess and reduce its impact on measures of shape. Acta Zool Acad Sci Hung 44 (1-2): 73-96.

Bourel B, Fleurisse L, Hédouin V, Cailliez JC, Creusy C, Gosset D, Goff ML. 2001. Immunohistochemical contribution to the study of morphine metabolism in Calliphoridae larvae and implications in forensic entomotoxicology. J Forensic Sci 46 (3): 596-599.

Carvalho CJB, Mello-Patiu CA. 2008. Key to the adults of the most common forensic species of Diptera in South America. Rev Bras Entomol. DOI: 10.1590/S0085-56262008000300012.

Chaiphongpachara T. 2018. Comparison of landmark- and outline-based geometric morphometrics for discriminating mosquito vectors in Ratchaburi Province, Thailand. Biomed Res Int 2018: 6170502. DOI $10.1155 / 2018 / 6170502$
Chaiphongpachara T, Laojun S, Jongvisuttisan N, Tubsamut P, Dasom A. 2018. A checklist of medically important flies (Order: Diptera) in the central region of Thailand. Biodiversitas 19 )6(: 2134-2139.

Chaiphongpachara T, Sriwichai P, Samung Y, Ruangsittichai J, Morales Vargas RE, Cui L, Sattabongkot J, Dujardin JP, Sumruayphol S. 2019. Geometric morphometrics approach towards discrimination of three member species of Maculatus group in Thailand. Acta Trop 192: 66-74.

Chaiphongpachara T, Laojun S. 2019. Annual variability of wing morphology in Culex sitiens Wiedemann (Diptera, Culicidae) mosquito vectors from the coastal area of Samut Songkhram Province, Thailand. Int J Parasitol Res 2019: 3978965. DOI: $10.1155 / 2019 / 3978965$

Changbunjong T, Sumruayphol S, Weluwanarak T, Ruangsittichai J. 2016. Landmark and outline-based geometric morphometrics analysis of three Stomoxys flies (Diptera: Muscidae). Folia Parasit 63: 37.

Dujardin JP, Slice D. 2007. Geometric morphometrics. Contributions to medical entomology. In: Tibayrenc, Encyclopedia of Infectious Diseases. Modern Technologies. Wiley, New York.

Dujardin J, Kaba D, Solano P, Dupraz M, Mccoy KD, Jaramillo-o N. 2014. Infection, genetics and evolution outline-based morphometrics, an overlooked method in arthropod studies. Infect Genet Evol 28: 704-714.

Dujardin JP. 2017. Modern Morphometrics of Medically Important Arthropods, Genetics and Evolution of Infectious Diseases. 2nd ed. Elsevier, Nederlands.

Dujardin JP. 2011. Modern Morphometrics of medically important insects. Genet Evol Infect Dis 2011: 473-501.

Gomez GF, Marquez EJ, Gutirrez LA, Conn JE, Correa MM. 2014. Geometric morphometric analysis of Colombian Anopheles albimanus (Diptera: Culicidae) reveals significant effect of environmental factors on wing traits and presence of a metapopulation. Acta Trop 135: 75-85.

Getachew S, Gebre-Michael T, Erko B, Balkew M, Medhin G. 2007. Nonbiting cyclorrhaphan flies (Diptera) as carriers of intestinal human parasites in slum areas of Addis Ababa, Ethiopia. Acta Trop 103 (3): 186-194.

Hall M, Wall R. 1995. Myiasis of humans and domestic animals. Adv Parasitol 35: 257-334.

Horenstein MB, Peretti A. 2012. Environmental conditions influence allometric patterns in the blowfly, Chrysomya albiceps. J Insect Sci 11: 131 .

Kaba D, Berté D, Ta BTD, Tellería J, Solano P, Dujardin J. 2017. The wing venation patterns to identify single tsetse flies. Infect Genet Evol 47: 132-139.

Kurahashi H, Chaiwong T. 2013. Keys to the flesh flies of Thailand, with description of a new species of Robineauella enderlein (Diptera: Sarcophagidae). J Entomol Zool Stud 64: 83-101

Killick-Kendrick R. 1996. Medical entomology for students. Trans R Soc Trop Med Hyg 90 )5(: 590.

Kuhl FP, Giardina CR. 1982. Elliptic fourier features of a closed contour. Comput Graph Image Process 18: 236-258.

Lord WD, Goff ML, Miller ML, Donnelly B, McDonough ET, Alexis JC. 2015. Isolation of amitriptyline and nortriptyline from fly puparia (Phoridae) and beetle exuviae (Dermestidae) associated with mummified human remains. J Forensic Sci 39 (5): 1305-1313.

Lorenz C, Almeida F, Almeida-Lopes F, Louise C, Pereira SN, Petersen V, Vidal PO, Virginio F, Suesdek L. 2017. Geometric morphometrics in mosquitoes: What has been measured. Infect Genet Evol 54: 205215.

Nazni WA, Seleena B, Lee HL, Jeffery JT, Rogayah TA, Sofian MA. 2005. Bacteria fauna from the house fly, Musca domestica (L.). Trop Biomed 22 (2): 225-231.

Pung JH, Shiuh FS, Chung YP, Hung YP, Chiou H. 2014. Identification of puparia of forensically important fly species (Diptera: Calliphoridae and Sarcophagidae) in Taiwan by scanning electron microscopy. J Forensic Sci 13 (1): 23-34.

Santillán-Guayasamín S, Villacís AG, Grijalva MJ, Dujardin JP. 2017. The modern morphometric approach to identify eggs of Triatominae 10 (1): 55.

Siriwattanarungsee S, Sukontason KL, Kuntalue B, Piangjai S, Olson JK, Sukontason K. 2005. Morphology of the puparia of the housefly, Musca domestica (Diptera: Muscidae) and blowfly, Chrysomya megacephala (Diptera: Calliphoridae). Parasitol Res 96 (3): 166-170. 
Sontigun N, Samerjai C, Sukontason K, Wannasan A, Amendt J, Tomberlin JK, Sukontason KL. 2019. Wing morphometric analysis of forensically important flesh flies (Diptera: Sarcophagidae) in Thailand. Acta Trop 190: 312-319.

Sontigun N, Sukontason KL, Zajac BK, Zehner R, Sukontason K, Wannasan A, Amendt J. 2017. Wing morphometrics as a tool in species identification of forensically important blowflies of Thailand. Parasit Vectors 10: 229.

Sumruayphol S, Apiwathnasorn C, Ruangsittichai J, Sriwichai P, Attrapadung S, Samung Y, Dujardin JP. 2016. DNA barcoding and wing morphometrics to distinguish three Aedes vectors in Thailand. Acta Trop. 159: 1-10.

Sukontason KL, Ngern-Klun R, Sripakdee D, Sukontason K. 2007. Identifying fly puparia by clearing technique: Application to forensic entomology. Parasitol Res 101 (5): 1407-1416.

Sungvornyothin S, Kumlert R, Paris DH, Prasartvit A, Sonthayanon P, Apiwathnasorn C, Morand S, Stekolnikov AA. 2018. Ticks and tickborne diseases geometric morphometrics of the scutum for differentiation of trombiculid mites within the genus Walchia (Acariformes: Prostigmata: Trombiculidae), a probable vector of scrub typhus. Ticks Tick Borne Dis 10 (2): 495-503.

Tan SW, Yap KL, Lee HL. 1997. Mechanical transport of rotavirus by the legs and wings of Musca domestica (Diptera: Muscidae). J Med Entomol 4 (5): 527-531.

Tumrasvin W, Shinonaga S. 1978. Studies on medically important flies in Thailand. V. On 32 species belonging to the subfamilies Muscinae and Stomoxyinae including the taxonomic keys (Diptera: Muscidae). Bull Tokyo Med Dent Univ 2: 77-81.

Wilke ABB, De Oliveira Christe R. Multini LC, Vidal PO, Wilk-Da-silva R, De Carvalho GC, Marrelli MT. 2016. Morphometric wing characters as a tool for mosquito identification. PLoS ONE 11 (8): e0161643. DOI: 10.1371/journal.pone.0161643.

Yap KL, Kalpana M, Lee HL. 2008. Wings of the common house fly (Musca domestica L.): Importance in mechanical transmission of Vibrio cholera. Trop Biomed 25 (1): 1-8. 